\title{
Erratum
}

\section{Erratum to: Estimation of potential gains from bank mergers: A novel two-stage cost efficiency DEA model}

\author{
Xiao Shi ${ }^{1,2}$, Yongjun $\mathrm{Li}^{1}$, Ali Emrouznejad ${ }^{3 *}$, Jianhui $\mathrm{Xie}^{1,4}$ and Liang Liang ${ }^{1}$ \\ ${ }^{1}$ School of Management, University of Science and Technology of China, He Fei 230026, An Hui, People's \\ Republic of China; ${ }^{2}$ School of Finance, Shandong University of Finance and Economics, \\ Jinan 250000, Shandong, People's Republic of China; ${ }^{3}$ Aston Business School, Aston University, Birmingham, \\ UK; and ${ }^{4}$ Lingnan College, Sun Yat-Sen University, Guangzhou 510275, Guangdong, People's Republic of China
}

Journal of the Operational Research Society (2017) 68(8), 983. doi:10.1057/s41274-017-0235-2;

published online 4 May 2017

\section{Correction to: Journal of the Operational Research Society (2017) doi: 10.1057/s41274-016-0106-2}

The article Estimation of potential gains from bank mergers: A novel two-stage cost efficiency DEA model, written by Xiao Shi, Yongjun Li, Ali Emrouznejad, Jianhui Xie and Liang Liang, was originally published electronically on the publisher's Internet portal (currently SpringerLink) on 23 February 2017 without open access. With the author(s)' decision to opt for Open Choice the copyright of the article changed on April 2017 to (C) The Author(s) 2017 and the article is forthwith distributed under the terms of the Creative Commons Attribution 4.0 International License (http:// creativecommons.org/licenses/by/4.0/), which permits use, duplication, adaptation, distribution and reproduction in any medium or format, as long as you give appropriate credit to the original author(s) and the source, provide a link to the Creative Commons License and indicate if changes were made.

*Correspondence: Ali Emrouznejad, Aston Business School, Aston University, Birmingham, UK.

E-mail: a.emrouznejad@aston.ac.uk 